\title{
Agreeing to Fight: An Explanation of the Democratic Peace*
}

\author{
John Wiggs Patty and Roberto A. Weber \\ Department of Social and Decision Sciences \\ Carnegie Mellon University
}

November 14, 2001

\begin{abstract}
In this paper we extend the well known "agreeing-to-disagree" and "notrade" results from economics and game theory to international relations. We show that two rational countries should never agree to go to war when war is inefficient and when rationality is common knowledge. We argue that this result might provide one possible explanation for the empirical finding, often referred to as the "Democratic Peace," that modern democracies rarely go to war with one another. We propose that the informational properties of pluralistic institutions (as opposed to oligarchies or dictatorships) lead to better decision-making by democracies and that democracies are therefore more likely to be the rational actors necessary for the "no-war" result. We discuss empirical evidence in support of this proposition.
\end{abstract}

*The authors acknowledge Christina Bicchieri and Kiron Skinner for helpful conversations on this topic. Thanks also to seminar participants at Carnegie Mellon University for helpful comments and suggetsions. 


\section{Introduction}

The Democratic Peace is one of the most widely discussed phenomena in International Relations. Put simply, the Democratic Peace hypothesis states that democracies are significantly less likely to fight wars with each other. ${ }^{1}$ While widely agreed with and supported in several studies (Oneal and Russett, 1999; Rousseau, et al., 1996; Bremer, 1992; Dixon, 1994; Russett, 1996a), the phenomenon has not been provided with a solid theoretical basis, leading some researchers to question its validity (Gowa, 1999; Schwarz and Skinner, 2000). Our contribution in this paper is to put forward a stylized model of international conflict that provides one possible explanation for the Democratic Peace. The paper's main point is that mutual disagreement about the likelihood of success in a military conflict can not explain the occurence of protracted warfare between two nations. In fact, war can only result when at least one of the following conditions holds: (1) at least one of the combatants is believed to prefer fighting and losing a war to not fighting at all or (2) at least one of the combatants actually prefers fighting and losing a war to not fighting at all. The implications of the model are broad: mutual understanding between nations - for instance, regarding one another's political institutions and

\footnotetext{
${ }^{1}$ A stronger - and more difficult to support - version of the law is that democracies never fight wars with each other.
} 
decision-making processes - can (and should) lead to reduced military conflict, regardless of the nations' unilateral interests, for nations whose leaders prefer not fighting to fighting and losing. In addition, the model predicts that, in conflict, nations whose leaders understand their opponent better than they are understood by their opponent's leaders will be more successful in war.

Our model is simply the extension of a well known result from economics and game theory. Aumann's (1976) "agreeing-to-disagree" result states that two rational decision makers should never disagree based solely on difference in information when their rationality is common knowledge. Put differently, two people should never maintain divergent beliefs based solely on having received different information - they should take into account what information must have led others to hold a different position and revise their beliefs until they converge. This result has been extended to speculative trade by Milgrom and Stokey (1982), who show that no such trade should occur based on differences in information.

We similarly extend this result to international relations. We show that, as long as war is inefficient and the rationality of nations is commonly known, two countries should never agree to go to war with each other based on different perceptions of who will win the war. We then argue that this result can be extended to provide a basis for the Democratic Peace as long as democracies are more likely 
to satisfy the rationality assumption of the model than non-democracies. We discuss existing empirical support for this assumption, both from experiments and comparative studies.

The next section of the paper discusses the literature that deals with the Democratic Peace. Section 3 discusses the theoretical literature related to our model of militarized conflict. The model and its application to the Democratic Peace is presented in Section 4 and conclusions are offered in Section 5.

\section{The Democratic Peace}

There are two main parts to the democratic peace: 1) democracies do not fight other democracies, and 2) democracies are no less likely to fight other non-democracies

(Rousseau, et al. 1996; Gartzke, 1998; Russett, 1996a). ${ }^{2}$ These two empirical regularities are supported by several studies. For instance, Oneal and Russett (1999) examine a period of over 100 years (1885 to 1992) and find that Kantian vari-

\footnotetext{
${ }^{2}$ While most of the empirical literature points to a strong effect of democracy - most of the large sample studies are in agreement that democracies do not fight one another - there is not unanimity among international relations scholars about the validity of the democratic peace. A group within the field, the realist school, argues that domestic institutions do not have the type of effect necessary on international relations for the democratic peace to obtain. Instead, they claim, international conflict is uniquely determined by the distribution of military capability and security concerns between countries. However, as Rousseau, et al., (1996) point out, the studies supporting the realist contention suffer from methodological flaws or small samples. For responses to the realist criticism, see Oneal and Russett (1999) and Rousseau, et al. (1996).
} 
ables (democracy, economic interdependence, membership in international organizations) decrease the likelihood of military conflict between two counries. ${ }^{3} \mathrm{Im}$ portantly, their analysis extends over the entire period and is not unique to any particular era, such as the inter-War period or the Cold War. Finally, they also find that conflict decreases as military strength becomes more uneven in a dyad, an empirical result that will be consistent with our model. Providing support for the dyadic nature of the phenomenon (which implies that democracies are less likely to fight one another, but no less likely to fight non-democracies), Maoz and Russett (1993) find that the support for the democratic peace (measured by the extent to which joint democratic dyads are less likely to enter or escalate conflict) is robust to several control variables and across several measures of conflict.

Rousseau, et al., (1996) also find that the democratic peace is largely dyadic: democracies are less likely to enter a conflict with each other, but are no less likely to enter conflicts with non-democracies. Specifically, they find that inititation of conflict, conditional on an existing crisis, is not significantly determined by a nation's own democracy, but rather by an interaction between own democracy and potential opponent's democracy. They interpret their results as evidence that:

\footnotetext{
${ }^{3}$ The Democratic Peace is often associated with the term "Kantian peace" due to Kant's argument that the blossoming of democracy, trade, and international cooperation would lead to decline in war.
} 
"Once a democracy is involved in an international crisis, it carefully distinguishes the type of state with which it is bargaining and adjusts its bargaining behavior accordingly. When faced with a democratic opponent, a democracy believes that its opponent shares its desire to avoid the use of force. Without reassurances, however, democracies will be less restrained concerning the use of force." (p. 527) Rousseau, et al., also find that a favorable balance of forces make it more likely that a particular country will initiate conflict.

Gartzke (1998) finds that the dyadic phenomenon of the democratic peace is not eliminated when affinity between countries is included as an explanatory variable. Specifically, he uses similarity of voting patterns in the United Nations as a measure of nations' affinity and then finds that this explains part of the propensity of countries to go to war. However, even when this affinity is included as an explanatory variable, there is still a significant effect of dyadic democracy in determining conflict.

While there is considerable evidence supporting the empirical phenomenon of the democratic peace, no strong theoretical basis has been provided for the result. Two of the main theories for why the democratic peace exists are: 1) that norms differ between democracies and non-democracies, with democratic political processes being more likely to rely on norms of peaceful resolution and 
compromise and 2) that political instutions in democratic countries hold leaders more directly accountable, meaning that these leaders are more likely to take into account the costs of conflict. ${ }^{4}$ However, detractors opponents of the existence of the democratic peace have attacked both of these theories and cite their "ad hoc" nature as one of the main reasons for doubting the existence of the phenomenon (Schwarz and Skinner, 2000).

In response to these criticisms, Bueno de Mesquita, et al., (1999) synthesize the main results associated with the democratic peace and present a theoretical basis for the phenonmenon. They posit seven empirical observations related to the democratic peace: 1) democracies fight with non-democracies, 2) conditional on fighting a war, democracies win more frequently, 3) when conflict first arises, democratic dyads are more likely to choose peaceful resolution, 4) democracies are more likely to start wars against autocracies than vice versa, 5) conditional on starting a war, democracies suffer less casualties and fight shorter wars, 6) transitional democracies are more likely to fight than stable regimes, and 7) larger democracies seem more constrained to avoid war than do smaller democracies. They present a model which they argue accounts for most of the empirical observations related to the democratic peace. In their model, leaders need to satisfy

\footnotetext{
${ }^{4}$ See, for instance, Russett (1996b) and Maoz and Russett (1993).
} 
a winning coalition of the actual voting electorate in order to remain in office. Therefore, in a conflict situation, these leaders need to decide first whether to go to war or negotiate a settlement and, if they fight, how much of the nation's resources to commit to the conflict. Specifically, in their model, the leader of an aggressive nation first decides whether or not to attack and, if so, what proportion of the nation's available resources to direct to the fight. If attacked, the other nation must similarly decide what proportion of available resources to commit to the war. The country that commits the most resources wins the war. Following the war, members of the winning coalition in each country decide whether or not to support the incumbent leader or defect to a rival. It directly follows from assumptions in their model that leaders in more democratic countries (those with larger potential participants in the election process and smaller winning coalitions) will, holding all else equal, be more likely to defeat a challenger than leaders in countries with smaller electorates and winning coalitions. In the equilibrium of the game, democracies will exert more effort in a war because leaders have more of an incentive to go after the large reward which can be divided among the large winning coalition than autocrats, who are more likely to stay in power if they withhold resources from the war and divide them among their smaller winning coalition. This means that wars are more costly for democracies and that demo- 
cratic leaders must be more certain of victory before intitiating conflict. Also as a result, democracies devote more effort to fighting wars, making it more unprofitable for two democracies to fight and therefore less likely. On the other hand, democracies are likely to attack non-democracies since they can expect that autocracies will respond with less effort.

Our approach is similar to that of Bueno de Mesquita, et al. in that we provide a stylized model of military conflict and use it to provide a theoretical basis for the democratic peace. Our argument offers an explanation of the dyadic nature of peace - in our model, combatants must agree to fight each other - and provides a set of conditions that imply that war will never occur in any dyad in which they are satisfied. Similarly to Bueno de Mesquita, et al., our explanation is consistent with the occurence of war but, according to our explanation, war can only happen when both of the nations' leaders believe that their opponent is both weaker and irrational.

\section{3 "Agreeing to disagree"}

Our theoretical argument relies on Aumann's (1976) familiar result in economics that two rational agents can never disagree based soley on differences in infor- 
mation when their rationality is common knowledge. The main result is simple. Suppose two people are trying to decide whether or not to bet on opposite sides of an event with two possible outcomes (meaning that only one of the two can win the bet if it is made). Then, if both people started out with the same model of the world (common priors) and only differ in the information that they received regarding the probability of the event, and if they are both rational Bayesian decision makers and this is common knowledge, then no such bet will ever be made.

We defer a more precise discussion of Aumann's result to later in the paper, but the intuition behind the result is simple: two people should not bet against each other in a zero-sum situation based solely on the belief that they are correct and the other party is wrong. If they both believe the other party to be rational (and this is common knowledge), then they have to realize that both sides can not be correct and that one of the two must have incorrect beliefs. This will lead the beliefs of both parties to converge as they take into account the information that the other side must have received in order to be willing to make the bet. The outcome of this process is that both sides will end up with the same beliefs, leading at least one party to decline to take the bet. This result has been applied by Milgrom and Stokey (1982) to show that speculative trade should never occur. They show that by a process similar to that used by Aumann, differences in information should 
never lead people to be willing to trade a speculative asset at a given price. We apply the same logic, modeling prolonged military conflict as a less than zero sum bet by two nations.

\section{A Model of War}

This section presents a simple, stylized model of protracted military conflict. There are two primary assumptions of the model: war is both risky and inefficient. War is risky in the sense that the victor is not known at the beginning of the conflict. War is inefficient because the final assignment of property rights could be established without the loss of life brought about by military conflict, for example.

For simplicity, we consider protracted military conflict between two nations, labelled A and B. The structure of interaction preceding military conflict in our model is as follows. Simultaneously, each nation decides whether to fight or defer. If either nation chooses to defer, then war does not occur. If both nations decide to fight, however, war occurs, and the winner is determined. The payoffs of the game are irrelevant so long as both nations prefer to defer than lose and war represents a less than zero-sum bet by the combatants. An example game tree is shown in Figure 1. 


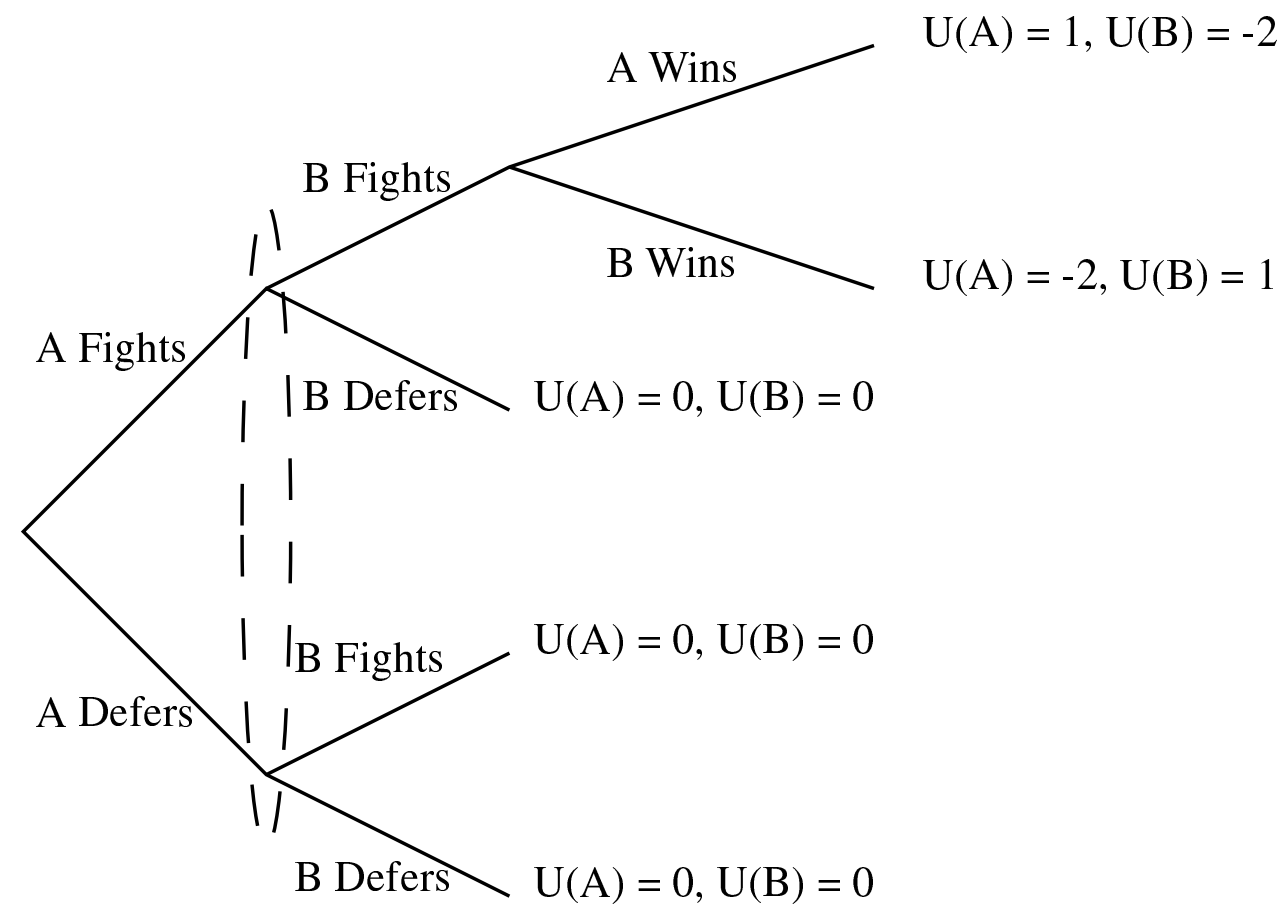

Figure 1: An Example of the War Game 
A key assumption in our model is that war is costly. Each nation incurs a fixed cost if war occurs. The spoils of victory may exceed this cost - if they did not, then it is obvious that no nation should ever go to war - but the sum of the two nations payoffs is less than zero. That is, the defeated nation would be willing to more than compensate the victorious nation in order to have not gone to war in the first place. Given the costliness of conflict, the combatants must believe that they have a high likelihood of winning the war. A necessary condition for a rational actor to be willing to fight a war in our model is that they believe the probability that they will emerge victorious is strictly greater than fifty percent. This implies that a necessary condition for war to occur is that both nations must believe that their probability of winning the war is greater than fifty percent. Our main result is that such beliefs (which are, of course, contradictory since the true probability that each country will win the war must sum to exactly one) can not be sustained in any equilibrium when both nations are rational, implying that war can not be an equilibrium outcome when the rationality of both players is common knowledge.

Definition 1 War is inefficient if it is known with certainty ex ante that the sum of the combatants' payoffs following a war will be strictly less than the sum of their payoffs in lieu of a war. 
According to our definition, war being inefficient implies there is a pre-war concession that both players would prefer to any post-war settlement. This is because war is akin to "leaving money on the table": protracted military conflict imposes significant and avoidable costs on both participants in search of an assignment of property rights that is attainable without warfare. (Notice that this is satisfied in the example game shown in Figure 1.)

Theorem 2 Suppose that war is inefficient, both players are rational, this rationality is common knowledge, and war requires both players consent. Then war is never an equilibrium outcome.

Proof: Suppose, contrary to the theorem, that war is an equilibrium outcome. Then it must be the case that the expected utility of war is no less than the expected utility of peace for both players, since either player may force the peaceful outcome by deferring. If war is inefficient then, by definition, the expected utility of war is less than the expected utility of peace for at least one (and perhaps both) of the two players. Hence, at least one player must strictly prefer deferring to going to war, implying that war between rational players can not be supported in equilibrium.

Notice that the theorem requires four conditions to be satisfied. First, war is 
assumed to be inefficient. Essentially, war is inefficient if there is a pre-war concession that would make both nations strictly better off than war. Second, both players are assumed to be rational. Rationality implies that the leaders seek to maximize their expected utility and update their beliefs based on all available information according to Bayes' rule. Third, common knowledge of the players' rationality implies that both players know that the other player is rational, that this knowledge of rationality is known to each player, and so forth. Finally, our requirement that war be mutually agreed upon in order to occur restricts the domain of the theorem to protracted military conflicts: wars in which both sides actually fight one another.

\subsection{Discussion of the Model and the Democratic Peace}

The purpose of our model of warfare is to illuminate one possible explanation for the Democratic peace. To do so, we argue that key assumptions of the above model and result - specifically, the rationality assumptions - are more likely to be satisfied by democracies. We argue that democracies are more likely to be better decion-making entities than autocracies and that, therefore, a dyad consisting of two democracies is most likely to satisfy the assumptions necessary for the above result to hold. We support this argument with two kinds of empirical evidence. 
First, there is empirical evidence that more participatory democracies are more likely to produce outcomes favorable to most voters. Pommerehne (1990) discusses several results, obtained by him and his co-authors, indicating that more direct democracies are more likely to produce results consistent with voter's preferences. For instance, one such set of studies finds that more direct and participatory democracies are more likely to produce outcomes closer to the median voter's preferences. Another finds that Swiss municipalities with more direct democracies are more efficient at public good (garbage collection) provision. In addition, government spending is significantly higher in representative than direct democracies (Pommerhene and Schneider, 1982).

Feld and Savioz (1997) question one of the assumptions in the most of the above studies - that less spending is better - and conduct a study to address this concern. Specifically, they compare the economic performance of Swiss cantons with and without elements of direct democracy (direct approval of fiscal matters by voters). Using GDP as the measure of economic performance, they find that cantons with direct participation perform better (between 5 and 15 percent) than those without.

Second, one of the ways in which the decision-making processes of democracies and dictatorships differ is that decision-making in decmoracies is likely to 
include effective participation by a much larger number of people. If large groups are more likely to behave rationally than individuals or small groups, then democracies are likely to benefit from these advantages of size. In fact, there is considerable experimental evidence that groups perform better than individuals across a wide variety of tasks. Social psychologists, organizational researchers, and more recently economics have addressed the question of whether groups behave more "rationally" across a wide variety of decision problems and and estimation tasks. While the studies vary greatly in the tasks they use and in the composition and size of groups, a common result across a majority of the research is that groups are generally better than the average, though not the best, individual.

In a survey of the psychological literature, Hill (1982) surveyed 139 studies on group versus individual performance, focusing on studies where group performance on a task was compared with the performance of individuals on the same task and where assignment to group versus individual condition was random. Overall, the survey provided consistent evidence that groups performed better than the average of individual performance, though not quite as well as the best group member. In tasks involving learning, groups consistently outperform individuals, making fewer errors and making better use of available information. Similarly, groups performed better in abstract problem solving, such as solving 
anagrams and spatial problems, though most of the difference could be explained by the fact that the group performed as well as the best member. However, in some tasks, such as difficult crossword puzzles, groups performed better than the best individual members. Not surprisingly, but importantly for our analysis, groups also fared better on tasks that required the realization of an insight necessary to solve the problem. This is significant for our analysis because the main intuition behind Aumann's result (that we both can't be making a good bet and that we should know this if were rational and this is common knowledge) is easy to follow once it is realized or explained.

Miner, Jr. (1984) similarly found that groups performed better than individuals in a complex decision task (involving a simulation of a "Winter Survival" situation), but not quite as well as the best individual in the group. This result was replicated by Cooke and Kernaghan (1987), who found that the result that groups perform better than individuals, though not better than the best individual in the group, obtained across several different aggregation rules for measuring performance of individuals.

In more recent work comparing the performance of groups and individuals in economic situations, Davis and Harless (1996) found that groups learned more quickly than individuals in a monopoly pricing task, producing higher average 
profits than "nominal groups" comprised of equal numbers of individuals. Also, Blinder and Morgan (2000) examined differences between group and individual decision making in a task where the objective is to identify a change in a random process underlying a series of observations, such as trying to figure out when an underlying causal process in the economy has changed. They find that groups do a better job - and earn significantly more money - than individuals.

Intuitively, the argument we are setting forth is that democratic decision-making should be more likely to recognize the gross inefficiencies embodied in prolonged military conflict and also more transparent to potential adversaries. Because of the greater involvement by a larger number of people in democracies, they are potentially closer to satisfying the classic form of rationality necessary for Aumann's and our results to obtain.

\section{Conclusion}

We have presented a stylized but useful model of international militarized conflict. The main result of this model is the recognition that, so long as war is inefficient, two rational individuals would never agree to fight one. This result is based on the logic of Aumann's famous "agreeing to disagree" result and carries with it some 
important implications concerning the decision processes that must logically precede and coincide with protracted bilateral military conflict. In particular, military conflict can not occur simply because the combatants possess different beliefs about their likelihood of winning the conflict; the rationality of the leaders of the nations involved in a conflict must not be common knowledge. This implication speaks to the importance of mutual understanding of politicial decision-making and political preferences across nations for sustained peace in the international arena. Furthermore, if one accepts that inclusive decision-making processes tend to lead to better decision-making in common value situations - as some of the empirical evidence we have referred to suggests - then the model implies that democratic dyads will be less likely to experience war than other dyads, but that democracies need not be characterized by a monadically lower level of militarized conflict than other regime types. These two implications are consistent witht the main results established by the considerable literature on the Democratic Peace.

Of course, our theory is a simplification of the real world. It is unlikely that Aumann's result directly replicates any real situations, and Milgrom and Stokey (1982) even provide a counterexample to their own result by showing that speculative trade should never take place (when in fact it does). However, the simplicity in our main point also makes it intuitively plausible: groups are more likely to be- 
have rationally than individuals because they have more information to aggregate and because it often only takes one person to point out the correct decision; because they are more rational, groups should be less likely to make "bad bets" than individuals, and therefore two groups should be less likely to agree to a speculative bet than two individuals or one individual and one group. Finally, escalation of bilateral conflict is similar to betting that your country will win this "bet." Therefore, we make the prediction, consistent with the empirical literature, that democracies, which are more like groups in that they allow for more aggregation of information and larger participation in decision-making, are less likely to go to war against one another.

While we present a simple theory of the Democratic Peace and we believe that this theory is at least part of a correct explanation of the empirical finding, we alllow that there are many other distinct causes of the phenomenon. Other explanations, such as the normative (democracies favor pacifism, especially towards other democracies) and the structural (democracies are more constrained by their institutions and therefore less able to go to war), are also undoubtedly part of the story. However, our theory adds to the existing literature in that it makes no normative claims of democratic "goodness." We do not argue that democracies are good and peace-loving and will therefore always try to find a peaceful resolution. 
On the contrary, we argue that democracies are perfectly willing to bet on war if they are pretty sure that they can win and they believe their opponent is making an irrational bet. Our claim is simply that democracies realize that other democracies are not likely to be that irrational. Similarly, in our theory, all countries democratic and nondemocratic - are equally free to choose to go to war. Even without additional structural constraints, however, our theory predicts that democratic institutions may be more restrained by choice when considering whether to go to war with another democracy.

At this point, it is important to recall that our theory does not predict that democracies will never go to war against one another. Aumann's theorem implies that two people will never bet on the outcome of a sporting event if they only care about making a winable bet. Similarly, in our argument two "rational" countries should never bet against each other in war if they only care about not losing a war. Of course, just as it might be the case that two rational people may bet on the game if they derive pleasure from betting or it makes the event more enjoyable for other reasons, it may also be the case that two rational democracies are willing to go to war against each other for reasons other than winning the war. If both countries (or even just one) have reasons for going to war other than simply to win, then war may no longer be a less-than-zero-sum bet - in which case our argument no longer 
holds. However, the fact that the data support the contention that democracies do not make bad "bets" implies that this is rarely the case.

Additionally, there is another very plausible scenario in which two rational democracies agreeing to fight a war is consistent with out theory. Namely, when both countries are democracies, but one (or both) believe the other not to be, then our conditions are not satisfied. In fact, Owen (1996) presents evidence that this might be the case: he points to several instances in which countries that may be considered democracies fought with each other, but only when the majority of citizens in one of the countries perceived the other not to be democratic. In our theory, misperception of a nation's decision-making process (i.e., whether it is a democracy or not) represents a failure of common knowledge of rationality. In such a case, Aumann's result does not apply and war can be "rational."

Finally, note that our theory is not truly about democracies. We do not propose that democracy per se leads to the democratic peace, but that dyads comprised of nations with more rational leaderships and better understandings of one another are less likely to fight one another. Therefore, similarly to Schwartz and Skinner (2001) we argue that the democratic peace does not have to be limited to democracies. Other causal factors might include the extent to which nations' media firms are allowed to report honestly and impartially concerning domestic and foreign 
affairs, the duration of diplomatic relations between two states, the dyadic stability of government leadership (properly construed to include the career bureaucrats as well as the political leaders of nations within a dyad), and the extent of cultural and economic ties between two nations.

\section{References}

Aumann, Robert J. 1976. "Agreeing to disagree." Annals of Statistics 4(6): 12361239.

Bennett, D. Scott, and Allan Stam. 2000. "EUGene: A conceptual manual." International Interactions 26:179-204.

Blinder, Alan S. and John Morgan. 2000. "Are two heads better than one? An experimental analysis of group vs. individual decision making.” NBER Working Paper 7909.

Bueno de Mesquita, B., J. D. Morrow, R. M. Siverson, A. Smith. 1999. "An institutional explanation of the democratic peace." American Political Science Review, 93(4): 791-807. 
Cooke, Robert A. and John A. Kerhnaghan. 1987. "Estimating the difference between group versus individual performance on problem-solving tasks." Group \& Organization Studies 12(3): 319-342.

Davis, Douglas D. and David W. Harless. 1996. “Group vs. individual performance in a price-searching experiment." Organizational Behavior and Human Decision Processes 66(2): 215-227.

Dixon, William J. 1994. "Democracy and the peaceful settlement of international conflict." The American Political Science Review, 88(1): 14-32.

Feld, Lars P. and Marcel R. Savioz. 1997. "Direct democracy matters for economic performance: An empirical investigation.” Kyklos 50(4): 507-538.

Gartzke, Erik. 1998. "Kant we all just get along? Opportunity, willingness and the origins of the democratic peace." American Journal of Political Science 42(1): 1-27.

Gowa, J. S. 1999. Ballots and Bullets. Princeton: Princeton University Press.

Hill, Gayle W. 1982. “Group versus individual performance: Are $N+1$ heads better than one?" Psychological Bulletin 91(3): 517-539. 
Maoz, Zeev and Bruce Russett. 1993. "Normative and structural causes of democratic peace, 1946-1986." The American Political Science Review 87(3): 624638.

Milgrom, Paul and Nancy Stokey. 1982. "Information, trade, and common knowledge." Journal of Economic Theory 26: 17-27

Miner, Jr., Frederick C. “Group versus individual decision making: An investigation of performance measures, decision strategies, and process losses/gains." Organizational Behavior and Human Performance 33: 112-124.

Monderer, D. and D. Samet. 1989. “Approximating common knowledge with common beliefs." Games and Economic Behavior 1: 170-190.

Neeman, Zvika. 1996. "Common Beliefs and the Existence of Speculative Trade." Games and Economic Behavior 16: 77-96.

Oneal, John R. and Bruce Russett. 1999. “The Kantian peace: The pacific benefits of democracy, interdependence, and international organizations, 1885-1992.” World Politics 52(1): 1-37. 
Owen, John R. 1996. "How liberalism produces democratic peace.” In Debating the Democratic Peace, eds. M. E. Brown, S. M. Lynn-Jones, and S. E. Miller. Cambridge, Massachusetts: The MIT Press.

Pommerehne, Werner W. 1990. “The empirical relevance of comparative institutional analysis." European Economic Review 34: 458-469.

Pommerehne, Werner W. and Friedrich Schneider. 1982. "Unbalance growth between public and private sectors: An empirical examination." In Public Finance and Public Employment, ed. Robert H. Haveman. Detriot, Michigan: Wayne State University Press.

Rousseau, D. L., C. Gelpi, D. Reiter and P. K. Huth. 1996. “Assessing the dyadic nature of the democratic peace." The American Political Science Review, 90(3): 512-533.

Rubinstein, Ariel and Asher Wolinsky. 1990. "On the logic of 'Agreeing to Disagree' Type Results.” Journal of Economic Theory 51: 184-193.

Russett, Bruce. 1996a. "The fact of the Democratic Peace." In Debating the Democratic Peace, eds. M. E. Brown, S. M. Lynn-Jones, and S. E. Miller. Cambridge, Massachusetts: The MIT Press. 
Russett, Bruce. 1996b. "Why Democratic Peace?" In Debating the Democratic Peace, eds. M. E. Brown, S. M. Lynn-Jones, and S. E. Miller. Cambridge, Massachusetts: The MIT Press.

Schwartz, Thomas and Kiron Skinner. 2000. "Democracy and the paradox of perpetual peace.” Unpublished manuscript. 